\title{
Is the Gap Closing? Comparison of Sociodemographic Disparities in COVID-19 Hospitalizations and Outcomes Between Two Temporal Waves of Admissions
}

\author{
Priscilla G. Wang ${ }^{1,2}$ (1) Nicholas M. Brisbon ${ }^{3,4} \cdot$ Harrison Hubbell ${ }^{3}$. John Pyhtila ${ }^{3}$. Gregg S. Meyer ${ }^{5} \cdot$ Po-Yu Lai $^{3}$. \\ Dellara F. Terry ${ }^{3,6}$
}

Received: 11 October 2021 / Revised: 6 January 2022 / Accepted: 23 January 2022 / Published online: 23 February 2022

(c) W. Montague Cobb-NMA Health Institute 2022

\begin{abstract}
Objective The COVID-19 pandemic has disproportionately impacted minority communities, yet little data exists regarding whether disparities have improved at a health system level. This study examined whether sociodemographic disparities in hospitalization and clinical outcomes changed between two temporal waves of hospitalized COVID-19 patients.

Methods This is a retrospective cohort study of primary care patients at Mass General Brigham (a large northeastern health system serving 1.27 million primary care patients) hospitalized in-system with COVID-19 between March 1, 2020, and March 1, 2021, categorized into two 6-month "wave" periods. We used chi-square tests to compare demographics between waves, and regression analysis to characterize the association of race/ethnicity and language with in-hospital severe outcomes (death, hospice discharge, intensive unit care need). Results Hispanic/Latino, Black, and non-English-speaking patients constituted 30.3\%, 12.5\%, and 29.7\% of COVID-19 admissions in wave $1(N=5844)$ and $22.2 \%, 9.0 \%$, and $22.7 \%$ in wave $2(N=4007)$, compared to 2019 general admission proportions of $8.8 \%, 6.3 \%$, and $7.7 \%$, respectively. Admissions from highly socially vulnerable census tracts decreased between waves. Non-English speakers had significantly higher odds of severe illness during wave 1 (OR 1.35; 95\% CI: 1.10, 1.66) compared to English speakers; this association was non-significant during wave 2 (OR 1.01; 95\% CI: 0.76, 1.36).

Conclusions Comparing two COVID-19 temporal waves, significant sociodemographic disparities in COVID-19 admissions improved between waves but continued to persist over a year, demonstrating the need for ongoing interventions to truly close equity gaps. Non-English-speaking language status independently predicted worse hospitalization outcomes in wave 1 , underscoring the importance of targeted and effective in-hospital supports for non-English speakers.
\end{abstract}

Keywords COVID-19 $\cdot$ Disparities $\cdot$ Sociodemographic $\cdot$ Race $\cdot$ Language

\section{Introduction}

The coronavirus disease 2019 (COVID-19) pandemic has disproportionately impacted communities of color in the USA. At the beginning of the pandemic, Hispanic/Latino

Priscilla G. Wang

pgwang@partners.org

Nicholas M. Brisbon

nicholas.brisbon@iqvia.com

Dellara F. Terry

lara_terry@atriushealth.org

1 Population Health Management, Mass General Brigham, Wang Ambulatory Care Center 634, 15 Parkman Street, Boston, MA 02114, USA and Black individuals nationally had 3.87 and 2.46 times the risk of testing positive for COVID-19 compared to White counterparts, respectively, according to the Centers for Disease Control and Prevention (CDC) [1]. Beyond infection risk, state and health system studies have

2 Division of General Internal Medicine, Massachusetts General Hospital, Boston, MA, USA

3 Data and Analytics Organization, Mass General Brigham, Boston, MA, USA

4 IQVIA, One IMS Drive, Plymouth Meeting, PA 19462, USA

5 Community Division and Value-Based Care, Mass General Brigham, Boston, MA, USA

6 Population Health Department, Atrius Health, 275 Grove St, Newton, MA 02466, USA 
demonstrated that Black, Hispanic/Latino, Asian, and other non-White individuals are more likely to be hospitalized from COVID-19 compared to White counterparts [2-4].

Disparities in clinical outcomes have been attributed to several causes. First, inequitable socioeconomic factors could increase risk for infectious exposure. For example, racial/ethnic minority individuals may be more likely to live in intergenerational homes or utilize public transit [5]. Second, upstream social determinants of health may lead to minority groups having higher rates of preexisting conditions associated with risk for severe COVID-19 infections [6]. Third, minority populations may present later for care, as noted by multiple studies finding delays in presentation among minority individuals after symptom onset and an increased likelihood of acute care needs at presentation compared to White individuals $[7,8]$. Biomarkers for inflammation (C-reactive protein, D-dimer, procalcitonin, lactate dehydrogenase, ferritin) and organ system dysfunction (neutrophil/lymphocyte ratio, lymphocyte percentage, troponin, creatinine) have been associated with COVID-19 illness severity and proposed as a means of measuring clinical severity at time of presentation $[9,10]$. Finally, minority group-related disparities in COVID-19 outcomes could result from differential or suboptimal care experiences once admitted, although multiple studies have not found differences in clinical outcomes during hospitalization after adjusting for clinical risk factors [8, 11].

The majority of existing literature on COVID-19-related disparities analyzes data from the first "wave" of cases (early to mid-2020) in the authors' respective health systems. Since then, states and communities have sought to address racial/ ethnic disparities in COVID-19-related outcomes via efforts such as improving disparity measurement, creating relief funds, and partnering with community organizations [12]. Most states have experienced a subsequent second wave of COVID-19 cases concomitantly or after implementing these proposed mitigation strategies. Yet little literature currently exists examining how disparities in demographics and outcomes of patients with COVID-19 have changed between waves of COVID-19 at the health system level. With an increased focus on health equity, have disparities improved across all demographic groups, or do certain groups continue to experience worse outcomes and warrant more targeted interventions and support?

Using data from a large New England health system, this analysis aimed to assess (1) whether sociodemographic characteristics of patients hospitalized with COVID-19 significantly changed from wave 1 to wave 2 , and whether previously noted disparities improved, and (2) whether the association between sociodemographic characteristics (race/ethnicity, language) and adverse COVID-19-related hospitalization outcomes changed between waves.

\section{Methods}

\section{Study Setting and Design}

Mass General Brigham (MGB) is a large Northeastern United States health system that serves a diverse population of 1.27 million primary care patients who live predominately in Massachusetts, as well as other New England states. Its inpatient facilities include two large academic medical centers, community and specialty hospitals, and rehabilitation facilities. Massachusetts experienced two significant "surges" in COVID-19 cases between March 2020 and March 2021. We divided this period into two "waves:" wave 1 (March 1, 2020-August 31, 2020) and wave 2 (September 1, 2020,-March 1, 2021). The September 1 cutoff point was chosen to include several weeks of COVID-19 cases before a clearly noticeable increase in the volume of COVID-19 cases in the "second surge" in Massachusetts (Supplementary Fig. 1) [13].

For inclusion, patients were required to (1) have a MGB primary care physician before March 1, 2020 (in order to more accurately capture medical history); (2) have been admitted to a MGB hospital facility between March 1, 2020, and March 1, 2021; and (3) have a documented PCR-based diagnosis of COVID-19 at time of admission. For analysis of pre-pandemic admission trends, sample patients were required to have a MGB primary care physician before January 1, 2019, and to have been admitted to an MGB facility during the 2019 calendar year. This study protocol was reviewed and approved by the MGB Institutional Review Board, which deemed the study minimal risk and waived need for informed consent.

\section{Outcome Measures}

The primary outcome was hospitalization with a diagnosis of COVID-19. Secondary outcomes included biomarker lab values at admission and development of severe illness during hospitalization (defined as requiring intensive care unit level of care including intubation, or experience of in-hospital death or discharge to hospice). A list of all biomarkers (selected a priori based on existing literature) and specific definitions for each severe illness category are provided in the Supplementary Methods.

\section{Covariates}

Our primary independent variables were race/ethnicity and language. Elicited by self-report at registration via two separate questions, race and ethnicity responses were combined into a joint variable: "White, non-Hispanic/Latino"; "Black, 
non-Hispanic/Latino"; "Other, non-Hispanic/Latino"; and "Hispanic/Latino"; the former three will henceforth be referred to as "White," "Black," and "Other". Sociodemographic covariates included age, sex, and health insurance type. Social Vulnerability Indices (SVI), CDC-created metrics for assessing the overall social vulnerability of a defined census tract, were determined using CDC methodology and home address, and categorized into quartiles in order of ascending vulnerability (see Supplementary Methods for detailed information regarding SVI calculation and interpretation) [14]. Clinical covariates were pre-specified based on prior literature correlating these conditions and COVID-19 severity, identified by ICD-10 codes, and included history of asthma, hypertension, diabetes (types 1 and 2), cancer, chronic kidney disease, chronic obstructive pulmonary disease (COPD), history of stroke, congestive heart failure, cardiovascular disease, tobacco use, and body mass index (BMI) [15]. BMI categories were coded using CDC definitions. All additional medical conditions were coded as binary variables.

\section{Statistical Analysis}

Data were obtained through an integrated electronic health record system (Epic Systems, Verona, WI) and analyzed using SAS Enterprise Guide version 7.13 (Cary, NC) and R version 4.0.3 (Vienna, Austria). Descriptive statistics for patient characteristics and biomarkers measured on admission were generated. Chi-square tests of independence were conducted in order to assess differences between time waves, and for secondary analysis examining the association between BMI and SVI quartile. To determine predictors of severe illness, two multivariable logistic regression models were fit in SAS, one model per wave, using the covariates above. Reference groups for categorical variables include "female" for biological sex, "White" for race/ ethnicity, "English" for language, and "commercial" for health insurance type. Because of low cell counts with the value of "unknown" for primary language, these were considered "missing" with listwise deletion for both models accounting for 47 missing observations for wave 1 and 13 for wave 2. Residuals were examined and both a deviance and Pearson goodness of fit test $(p>0.05)$ indicated adequate model fit. Predictive ability was assessed using the $c$ statistic (wave $1=0.73$; wave $2=0.75$ ). Potential multicollinearity was examined for all with generalized variance inflation factors (GVIF) using the R package "car" [16]. All GVIF values were $<2.0$, indicating low concern for multicollinearity. Models used two-sided statistical tests, with a $p$ value $<0.05$ considered statistically significant.

\section{Results}

\section{Characteristics of Patients Hospitalized with COVID-19}

A total of 5844 MGB primary care patients (225 patients/ week) were hospitalized with a diagnosis of COVID-19 in wave 1, compared with 4007 (154 patients/week) in wave 2 . In both waves, patients were more likely to be older (mean age 58.2, SD 20.4 years), female (52.8\%), and non-Hispanic White $(52.5 \%)$. In both waves, Hispanic/Latino and nonHispanic Black patients were disproportionately represented among COVID-19 admissions, compared with pre-pandemic MGB admission rates. In 2019, for example, Hispanic/Latino and non-Hispanic Black patients comprised $8.8 \%$ and $6.3 \%$ of MGB admissions, respectively (Supplementary Table 1). In comparison, these patients comprised $30.3 \%$ and $12.5 \%$ of COVID-19-related admissions in wave 1 and $22.2 \%$ and $9.0 \%$ in wave 2. Additionally, while non-English-speaking patients accounted for $7.7 \%$ of pre-pandemic admissions; they constituted $29.7 \%$ and $22.7 \%$ of admissions in waves 1 and 2 , respectively.

There were statistically significant differences between waves in age, race/ethnicity, primary language, insurance type, social vulnerability index, nursing home admission, smoking status and number of chronic conditions at admission. Compared to wave 1 , wave 2 admissions included a higher percentage of non-Hispanic White patients (59.1\%, versus $47.9 \%$ in wave 1) and English-speaking patients (77.3\%, versus $70.3 \%$ ) (Table 1 ).

Regarding community-based disparities for patients admitted with COVID-19, in wave 1, predominately Black and Latino communities in Massachusetts experienced disproportionately high rates of COVID-19 infection and hospitalization relative to their population size [13]. In wave 1, the five most represented home cities were Lynn, Boston, Chelsea, Revere, and Salem, localities with high poverty rates and with higher proportions of minority and nonEnglish-speaking individuals compared with state averages (Tables 2 and 3). In wave 2, four of these five remained in the top five most represented towns. Overall, communitybased social vulnerability measures (SVI, a CDC-based metric) decreased between waves: in wave 1, $44.9 \%$ of admitted patients had home residences in the most vulnerable quartile of census tracts (SVI 0.75-1; Table 1), compared with $34.4 \%$ in wave 2 .

\section{Assessing Disease Severity at Presentation}

Given the possibility that patients could have presented at different times in their clinical course in wave 1 versus wave 2 (for example, due to increased awareness about 
Table 1 Characteristics of patients admitted with COVID-19 diagnosis in both time waves

\begin{tabular}{|c|c|c|c|}
\hline \multirow[t]{2}{*}{ Characteristics } & \multicolumn{2}{|c|}{ Number $(\%)$ of patients } & \multirow[t]{2}{*}{$p$ value* } \\
\hline & $\begin{array}{l}\text { Wave } 1 \\
(n=5844)\end{array}$ & $\begin{array}{l}\text { Wave } 2 \\
(n=4007)\end{array}$ & \\
\hline \multicolumn{4}{|l|}{ Illness severity } \\
\hline Severe & $1360(23.3)$ & $571(14.2)$ & \multirow[t]{2}{*}{$<.001$} \\
\hline Not severe & $4484(76.7)$ & $3436(85.7)$ & \\
\hline \multicolumn{4}{|l|}{ Mortality } \\
\hline Deceased or hospice & $568(9.7)$ & $227(5.7)$ & \multirow[t]{2}{*}{$<.001$} \\
\hline Discharged home & $5276(90.3)$ & $3780(94.3)$ & \\
\hline \multicolumn{4}{|l|}{ Age } \\
\hline $0-44$ & $1481(25.3)$ & $1064(26.5)$ & \multirow[t]{5}{*}{.006} \\
\hline $45-54$ & $860(14.7)$ & $541(13.5)$ & \\
\hline $55-64$ & $1177(20.1)$ & $716(17.9)$ & \\
\hline $65-74$ & $976(16.7)$ & $677(16.9)$ & \\
\hline $75+$ & $1350(23.1)$ & $1009(25.2)$ & \\
\hline \multicolumn{4}{|l|}{ Sex } \\
\hline Male & $2765(47.3)$ & $1883(47.0)$ & \multirow[t]{2}{*}{.75} \\
\hline Female & $3079(52.7)$ & $2124(53.0)$ & \\
\hline \multicolumn{4}{|l|}{ Race/ethnicity } \\
\hline White & $2799(47.9)$ & $2370(59.1)$ & \multirow[t]{5}{*}{$<.001$} \\
\hline Black & $729(12.5)$ & $360(9.0)$ & \\
\hline Other & $398(6.8)$ & $302(7.5)$ & \\
\hline Hispanic & $1770(30.3)$ & $890(22.2)$ & \\
\hline Unknown & $148(2.5)$ & $85(2.1)$ & \\
\hline \multicolumn{4}{|l|}{ Primary language } \\
\hline English & $4106(70.3)$ & $3098(77.3)$ & \multirow[t]{3}{*}{$<.001$} \\
\hline Non-English & $1692(28.9)$ & $896(22.4)$ & \\
\hline Unknown & $46(0.8)$ & $13(0.3)$ & \\
\hline \multicolumn{4}{|l|}{ Insurance type } \\
\hline Commercial & $2748(47.0)$ & $2074(51.8)$ & \multirow[t]{4}{*}{$<.001$} \\
\hline Medicaid & $1231(21.1)$ & $701(17.5)$ & \\
\hline Medicare & $1755(30.0)$ & $1158(28.9)$ & \\
\hline Other & $110(1.9)$ & $74(1.8)$ & \\
\hline \multicolumn{4}{|l|}{ SVI } \\
\hline$(0-.25)$ & $734(12.6)$ & $680(17.0)$ & \multirow[t]{5}{*}{$<.001$} \\
\hline$(.25-.50)$ & $886(15.2)$ & $798(19.9)$ & \\
\hline$(.50-.75)$ & $1224(20.9)$ & $807(20.1)$ & \\
\hline$(.75-1)$ & $2627(44.9)$ & $1380(34.4)$ & \\
\hline Unknown & $373(6.4)$ & $342(8.5)$ & \\
\hline \multicolumn{4}{|l|}{ Admit source } \\
\hline Nursing home facility & $174(3.0)$ & $41(1.0)$ & \multirow[t]{2}{*}{$<.001$} \\
\hline Other & $5670(97.0)$ & $3966(99.0)$ & \\
\hline \multicolumn{4}{|l|}{ Smoking status } \\
\hline Current/former smoker & $2232(38.2)$ & $1472(36.7)$ & \multirow[t]{3}{*}{.004} \\
\hline Non-smoker & $3300(56.5)$ & $2368(59.1)$ & \\
\hline Unknown & $312(5.3)$ & $167(4.2)$ & \\
\hline
\end{tabular}

COVID-19), biomarkers of severity of COVID-19-related illness at the time of hospitalization were compared between waves. There were statistically significant differences
Table 1 (continued)

\begin{tabular}{llll}
\hline Characteristics & \multicolumn{2}{l}{ Number $(\%)$ of patients } & \multirow{2}{*}{$p$ value* } \\
\cline { 2 - 3 } & $\begin{array}{l}\text { Wave } 1 \\
(n=5844)\end{array}$ & $\begin{array}{l}\text { Wave } 2 \\
(n=4007)\end{array}$ & \\
\hline BMI & & & \\
$\quad$ Normal (18.5-25) & $1352(23.1)$ & $965(24.1)$ & .16 \\
$\quad$ Underweight $(<18.5)$ & $166(2.8)$ & $122(3.0)$ & \\
Overweight $(25-30)$ & $1761(30.1)$ & $1172(29.2)$ & \\
Class 1 obese $(30-35)$ & $1258(21.5)$ & $815(20.3)$ & \\
Class 2 obese $(35-40)$ & $616(10.5)$ & $408(10.2)$ & \\
Class 3 obese $(40+)$ & $403(6.9)$ & $329(8.2)$ & \\
$\quad$ Unknown & $288(4.9)$ & $196(4.9)$ & \\
Chronic conditions & & & \\
0 & $2114(36.2)$ & $1626(40.6)$ & $<.001$ \\
1 & $1139(19.5)$ & $837(20.9)$ & \\
$2+$ & $2591(44.3)$ & $1544(38.5)$ & \\
\hline
\end{tabular}

$S V I$, Social Vulnerability Index; $B M I$, body mass index

${ }^{*} p$ values for wave 1 versus wave 2 were calculated using a $X^{2}$ test for all variables

Table 2 Top five geographic locations of patients admitted with COVID-19

\begin{tabular}{lll}
\hline $\begin{array}{l}\text { Rank by admission } \\
\text { volume }\end{array}$ & \multicolumn{2}{l}{ City: $^{\text {a number }(\%) \text { of patients }}$} \\
\cline { 2 - 3 } & $\begin{array}{l}\text { Wave 1 } \\
(n=5844)\end{array}$ & $\begin{array}{l}\text { Wave 2 } \\
(n=4007)\end{array}$ \\
\hline 1 & Lynn: $777(13.3)$ & Lynn: 442 (11.0) \\
2 & Boston: 766 (13.1) & Boston: 362 (9.0) \\
3 & Chelsea: $393(6.7)$ & Revere: $169(4.2)$ \\
4 & Revere: $245(4.2)$ & Salem: $145(3.6)$ \\
5 & Salem: $185(3.2)$ & Peabody: $127(3.2)$ \\
\hline
\end{tabular}

${ }^{a}$ All cities listed are located in the state of Massachusetts in the USA

between the distribution of these lab values in wave 1 versus wave 2 (Table 4). In general, with the exception of neutrophil and lymphocyte values, wave 2 lab value distributions appeared shifted toward lab values closer to normal ranges (for example, $60.9 \%$ of patients in wave 1 had an admission ferritin value of $<500$, compared to $70.2 \%$ in wave 2 ). There were no significant differences between waves in regard to time from hospital admission to ICU transfer, another potential proxy measure for illness severity at time of admission (Table 4).

\section{Predictors of Severe Illness Following Hospitalization}

The proportion of admitted patients developing severe illness during hospitalization decreased from wave 1 to wave $2(23.3$ to $14.2 \%)$. In logistic regression models adjusting 
Table 3 Census demographics of top geographic admission sources $^{\text {a }}$

\begin{tabular}{lccllc}
\hline City & \% of inhabitants & & Poverty rate \\
\cline { 2 - 5 } & Hispanic/Latino & $\begin{array}{l}\text { Black, non- } \\
\text { Hispanic }\end{array}$ & Foreign-born & $\begin{array}{l}\text { Non-English } \\
\text { home language }\end{array}$ \\
\hline $\begin{array}{l}\text { City average in } \\
\text { Massachusetts }\end{array}$ & $12.4 \%$ & $9.0 \%$ & $16.8 \%$ & $23.8 \%$ & $9.4 \%$ \\
Lynn & $42.8 \%$ & $13.7 \%$ & $36.7 \%$ & $53.6 \%$ & $16.6 \%$ \\
Boston & $19.8 \%$ & $25.2 \%$ & $28.3 \%$ & $37.7 \%$ & $18.9 \%$ \\
Chelsea & $67.0 \%$ & $6.4 \%$ & $45.4 \%$ & $69.8 \%$ & $18.1 \%$ \\
Revere & $33.6 \%$ & $5.5 \%$ & $39.0 \%$ & $51.7 \%$ & $12.7 \%$ \\
Salem & $17.8 \%$ & $6.6 \%$ & $14.6 \%$ & $22.0 \%$ & $14.7 \%$ \\
Peabody & $9.9 \%$ & $3.8 \%$ & $15.4 \%$ & $21.3 \%$ & $8.6 \%$ \\
\hline
\end{tabular}

${ }^{\text {a }}$ Statistics from United States Census 2019 Data; Census.Gov for demographic and baseline clinical characteristics, race/ ethnicity was not a significant independent predictor in either wave (Table 5). Non-English-speaking patients had significantly higher odds of severe illness during wave 1 (OR 1.35; 95\% CI: 1.10, 1.66) compared to English-speaking patients, but not during wave 2. Clinically, diabetes and class 3 obesity were independently associated with significantly increased odds of severe illness in both waves (OR 1.56, 95\% CI: 1.25, 1.96; OR 1.64, 95\% CI 1.13, 2.37, respectively). Examining the distribution of BMI and class 3 obesity rates between patients from different SVI quartiles, there was a statistically significant association between BMI and SVI quartile (Supplementary Table 2).

\section{Characterizing Patients Who Died In-Hospital from COVID-19}

In wave 1, 9.7\% (568) of patients hospitalized with COVID19 died in hospital or were discharged to hospice, versus $5.7 \%$ (227) in wave 2. There were no statistically significant differences in demographic or clinical characteristics between patients in different waves (Table 6).

\section{Discussion}

This study compared sociodemographic characteristics of patients hospitalized with COVID-19 at a large Northeastern United States health system during two waves of COVID-19 cases. While most US-based analyses of COVID-19-related disparities have focused on the first historical surge, this analysis adds to the literature by examining whether known health system-level disparities have changed since the beginning of the pandemic in the context of increased public and health system awareness. Our analysis found significant hospitalization-based sociodemographic disparities during the initial wave of COVID-19-related admissions. Wave 1 patients originated predominately from highly socially vulnerable neighborhoods, and racial/ethnic minority and non-English-speaking patients were very disproportionately represented among COVID-19 admissions compared to pre-pandemic rates. Hispanic/Latino patients, for example, comprised close to one-third of all COVID-19-related admissions, more than three times their admission proportion pre-pandemic. Similarly, the proportion of admitted non-English-speaking patients increased fourfold from prepandemic rates.

While the absolute rates of admissions from minority groups and socially vulnerable communities decreased from wave 1 to wave 2 , wave 2 numbers remained greatly skewed toward minority and immigrant populations, suggesting significant persistent disparities. Towns with large low-income minority populations continued to account for the majority of COVID-19 admissions, with minimal change between waves 1 and 2. For example, the most highly represented city in both waves, Lynn, has a population that is $42.8 \%$ Hispanic and $36.7 \%$ foreign-born, and with $53.6 \%$ speaking a language other than English at home, compared with average rates of $12.4 \%, 16.8 \%$, and $23.8 \%$ in Massachusetts, respectively [17].

Despite the persistent disparities noted above, clinical outcomes during hospitalization improved from wave 1 to wave 2. Fewer patients admitted with COVID-19 in wave 2 developed severe illness or died compared to wave 1. Patients may have been more clinically well at time of presentation in wave 2 compared to wave 1 , as suggested by a slight skew of most admission lab predictors toward clinically normal values. This may reflect increased understanding among community members or medical workers regarding the importance of earlier presentation for medical care. Additionally, increased access to novel therapeutics and vaccinations could have contributed to improved outcomes, the former by improving in-hospital treatment and the latter by potentially reducing the severity of disease at time of presentation. The only independent clinical predictors of poor outcome that remained significant across both waves 
Table 4 Markers of COVID-19 illness severity at time of admission

\begin{tabular}{|c|c|c|c|}
\hline \multirow[t]{2}{*}{ Biomarkers } & \multicolumn{2}{|c|}{ Number $(\%)$ of patients } & \multirow[t]{2}{*}{$p$ value } \\
\hline & $\begin{array}{l}\text { Wave } 1 \\
(n=5844)\end{array}$ & $\begin{array}{l}\text { Wave } 2 \\
(n=4007)\end{array}$ & \\
\hline \multicolumn{4}{|l|}{ Troponin, ng/mL } \\
\hline$<0.4$ & $1716(29.4)$ & $1508(37.6)$ & \multirow[t]{2}{*}{$<.001$} \\
\hline $0.4+$ & $4128(70.6)$ & $2499(62.4)$ & \\
\hline \multicolumn{4}{|l|}{ C-reactive protein, $\mathrm{mg} / \mathrm{L}$} \\
\hline $0-15$ & $3424(58.6)$ & $2609(65.1)$ & \multirow[t]{4}{*}{$<.001$} \\
\hline $15-100$ & $1746(29.9)$ & $1094(27.3)$ & \\
\hline $100-200$ & $489(8.4)$ & $234(5.8)$ & \\
\hline $200+$ & $185(3.2)$ & $70(1.7)$ & \\
\hline \multicolumn{4}{|l|}{ Creatinine, $\mathrm{mg} / \mathrm{dL}$} \\
\hline$<1.1$ & $4654(79.6)$ & $3292(82.2)$ & \multirow[t]{3}{*}{$<.001$} \\
\hline $1.1-2$ & $790(13.5)$ & $530(13.2)$ & \\
\hline $2+$ & $400(6.8)$ & $185(4.6)$ & \\
\hline \multicolumn{4}{|l|}{ D-Dimer, $\mathrm{ng} / \mathrm{mL}$} \\
\hline $0-250$ & $2951(50.5)$ & $2379(59.4)$ & \multirow[t]{5}{*}{$<0.001$} \\
\hline $250-500$ & $609(10.4)$ & $434(10.8)$ & \\
\hline $500-1000$ & $890(15.2)$ & $495(12.3)$ & \\
\hline $1000-2500$ & $906(15.5)$ & $457(11.4)$ & \\
\hline $2500+$ & $488(8.3)$ & $242(6.0)$ & \\
\hline \multicolumn{4}{|l|}{ Ferritin, ng/mL } \\
\hline $0-300$ & $3434(58.8)$ & $2572(64.2)$ & \multirow[t]{5}{*}{$<.001$} \\
\hline $300-500$ & $692(11.8)$ & $443(11.1)$ & \\
\hline $500-1000$ & $903(15.4)$ & $572(14.3)$ & \\
\hline $1000-2500$ & $640(10.9)$ & $333(8.3)$ & \\
\hline $2500+$ & $175(3.0)$ & $87(2.2)$ & \\
\hline \multicolumn{4}{|l|}{ Procalcitonin, $\mathrm{ng} / \mathrm{mL}$} \\
\hline$<0.5$ & $5352(91.6)$ & $3863(96.4)$ & \multirow[t]{2}{*}{$<.001$} \\
\hline $0.5+$ & $492(8.4)$ & $144(3.6)$ & \\
\hline \multicolumn{4}{|c|}{ Lactate dehydrogenase, units/L } \\
\hline$<273$ & $4081(69.8)$ & $3016(75.3)$ & \multirow[t]{3}{*}{$<.001$} \\
\hline $273+$ & $1747(29.9)$ & $985(24.6)$ & \\
\hline Missing & $16(0.3)$ & $6(0.1)$ & \\
\hline \multicolumn{4}{|c|}{ Absolute lymphocyte count, cells $/ \mu \mathrm{L}$} \\
\hline Low $(<1)$ & $2296(39.3)$ & $1810(45.2)$ & \multirow[t]{3}{*}{$<.001$} \\
\hline Normal (1-4.8) & $3500(59.9)$ & $2164(54.0)$ & \\
\hline High $(4.8+)$ & $48(0.8)$ & $33(0.8)$ & \\
\hline \multicolumn{4}{|c|}{ Absolute neutrophil count, cells $/ \mu \mathrm{L}$} \\
\hline Low $(<1.5)$ & $1016(17.4)$ & $801(20.0)$ & \multirow[t]{3}{*}{$<.001$} \\
\hline Normal (1.5-8) & $4128(70.6)$ & $2645(66.0)$ & \\
\hline $\operatorname{High}(8+)$ & $700(12.0)$ & $561(14.0)$ & \\
\hline \multicolumn{4}{|l|}{ Lymphocyte percentage } \\
\hline Low $(<20 \%)$ & $3136(53.7)$ & $2377(59.3)$ & \multirow[t]{3}{*}{$<0.001$} \\
\hline Normal (20-40\%) & $2261(38.7)$ & $1387(34.6)$ & \\
\hline High $(>40 \%)$ & 447 (7.6) & $243(6.1)$ & \\
\hline Neutrophil percentage & & & \\
\hline Low $(<40 \%)$ & $1048(17.9)$ & $810(20.2)$ & $<0.001$ \\
\hline Normal (40-60\%) & $1506(25.8)$ & $779(19.4)$ & \\
\hline $\operatorname{High}(>60 \%)$ & $3290(56.3)$ & $2418(60.3)$ & \\
\hline
\end{tabular}

Table 4 (continued)

\begin{tabular}{|c|c|c|c|}
\hline \multirow[t]{2}{*}{ Biomarkers } & \multicolumn{2}{|c|}{ Number (\%) of patients } & \multirow[t]{2}{*}{$p$ value* } \\
\hline & $\begin{array}{l}\text { Wave } 1 \\
(n=5844)\end{array}$ & $\begin{array}{l}\text { Wave } 2 \\
(n=4007)\end{array}$ & \\
\hline \multicolumn{4}{|l|}{ Clinical trajectory } \\
\hline \multicolumn{4}{|c|}{ Time to ICU admission $^{\mathrm{a}}$} \\
\hline Direct admit & $61(7.2)$ & $26(7.3)$ & 0.38 \\
\hline$<24 \mathrm{~h}$ & $482(57.0)$ & $192(54.1)$ & \\
\hline 1-3 days & $148(17.5)$ & $56(15.8)$ & \\
\hline $3-6$ days & $116(13.7)$ & $54(15.2)$ & \\
\hline $7+$ days & $39(4.6)$ & $27(7.6)$ & \\
\hline \multicolumn{4}{|c|}{$\begin{array}{l}I C U \text {, intensive care unit } \\
* p \text { values for wave } 1 \text { versus wave } 2 \text { were calculated using a } X^{2} \text { test for } \\
\text { all variables }\end{array}$} \\
\hline \multicolumn{4}{|c|}{$\begin{array}{l}\text { a Time calculated from time of admission to time of ICU transfer; } \\
\text { patients not admitted to ICU are excluded }\end{array}$} \\
\hline
\end{tabular}

were diabetes and class III obesity. BMI was significantly associated with patients' SVI, providing an example of how social determinants might translate directly into increased risk for severe COVID-19-related outcomes.

Despite disproportionate representation among individuals hospitalized of racial/ethnic minority groups, race/ ethnicity was not a significant predictor of severe illness once hospitalized in either wave after covariate adjustment. This finding is consistent with the majority of the literature, and further emphasizes the lack of evidence regarding racebased genetic predispositions for worse outcomes among certain racial groups. A novel finding of this study was that non-English-speaking status during wave 1 significantly and independently predicted severe illness and was associated with 35\% higher odds of severe illness outcomes including death. Prior literature has shown increased risk of hospitalization among non-English speakers diagnosed with COVID19 on a population level,but few studies have independently associated language status with COVID-19 illness severity on a patient level $[18,19]$.

How might language status impact outcomes following hospitalization, independent of comorbidities or other sociodemographic factors? First, language could serve as a proxy for social risk factors leading to delays in clinical presentation. For example, non-English-speaking individuals are likely to be immigrants, and might therefore be less aware of how to navigate the US health system or have less access to digital- and English-language-based primary care educational materials or public health announcements. Beyond upstream risk factors, however, hospitalized non-English speakers could experience non-optimal care inpatient due to challenges communicating symptoms or providing relevant history. During the first wave of the COVID-19 pandemic, our health system identified significant challenges 
Table 5 Adjusted odds ratios of severe COVID-19 illness following hospital admission ${ }^{\mathrm{a}}$

\begin{tabular}{|c|c|c|c|c|c|c|}
\hline \multirow[t]{2}{*}{ Patient characteristic } & \multicolumn{3}{|l|}{ Wave $1(n=5798)$} & \multicolumn{3}{|l|}{ Wave $2(n=3994)$} \\
\hline & $\begin{array}{l}\text { OR } \\
(95 \% \mathrm{CI})\end{array}$ & SE & $p$ value & $\begin{array}{l}\text { OR } \\
(95 \% \mathrm{CI})\end{array}$ & SESE & $p$ value \\
\hline Age & $1.02(1.02,1.03)$ & 0.002 & $<0.001$ & $1.02(1.02,1.03)$ & 0.003 & $<0.001$ \\
\hline \multicolumn{7}{|l|}{ Sex } \\
\hline Male & $1.95(1.70,2.23)$ & 0.07 & $<0.001$ & $2.00(1.65,2.44)$ & 0.10 & $<0.001$ \\
\hline Female & Ref & Ref & Ref & Ref & Ref & Ref \\
\hline \multicolumn{7}{|l|}{ Race/ethnicity } \\
\hline White & Ref & Ref & Ref & Ref & Ref & Ref \\
\hline Black & $1.07(0.87,1.33)$ & 0.11 & 0.51 & $1.21(0.86,1.70)$ & 0.17 & 0.28 \\
\hline Other & $1.00(0.74,1.33)$ & 0.15 & 0.97 & $1.64(1.12,2.40)$ & 0.19 & 0.01 \\
\hline Hispanic & $1.00(0.79,1.25)$ & 0.12 & 0.99 & $1.07(0.77,1.49)$ & 0.17 & 0.69 \\
\hline Unknown & $1.12(0.70,1.81)$ & 0.24 & 0.63 & $1.66(0.91,3.02)$ & 0.30 & 0.10 \\
\hline \multicolumn{7}{|l|}{ Language } \\
\hline English & Ref & Ref & Ref & Ref & Ref & Ref \\
\hline Non-English & $1.35(1.10,1.66)$ & 0.10 & 0.003 & $1.01(0.76,1.36)$ & 0.15 & 0.92 \\
\hline \multicolumn{7}{|l|}{ Insurance type } \\
\hline Commercial & Ref & Ref & Ref & Ref & Ref & Ref \\
\hline Medicare & $1.27(1.08,1.49)$ & 0.08 & 0.003 & $1.33(1.06,1.67)$ & 0.11 & 0.01 \\
\hline Medicaid & $1.00(0.82,1.23)$ & 0.10 & 0.97 & $0.95(0.68,1.32)$ & 0.17 & 0.75 \\
\hline Other & $0.75(0.42,1.34)$ & 0.30 & 0.33 & $0.60(0.22,1.61)$ & 0.50 & 0.31 \\
\hline \multicolumn{7}{|l|}{ Tobacco exposure } \\
\hline Non-smoker & Ref & Ref & Ref & Ref & Ref & Ref \\
\hline Smoker/former smoker & $1.05(0.91,1.21)$ & 0.07 & 0.52 & $1.35(1.10,1.66)$ & 0.10 & 0.004 \\
\hline Unknown & $2.18(1.60,2.97)$ & 0.16 & $<0.001$ & $3.37(2.19,5.19)$ & 0.22 & $<0.001$ \\
\hline \multicolumn{7}{|l|}{ BMI } \\
\hline$<18.5$ & $1.42(0.98,2.06)$ & 0.19 & 0.07 & $1.16(0.65,2.08)$ & 0.30 & 0.61 \\
\hline $18.5-25$ & Ref & Ref & Ref & Ref & Ref & Ref \\
\hline $25-29.9$ & $0.88(0.73,1.04)$ & 0.09 & 0.14 & $0.71(0.55,0.92)$ & 0.13 & 0.01 \\
\hline $30-34.9$ & $0.92(0.76,1.12)$ & 0.10 & 0.40 & $0.94(0.71,1.24)$ & 0.14 & 0.66 \\
\hline $35-39.9$ & $1.14(0.89,1.45)$ & 0.12 & 0.30 & $1.20(0.85,1.70)$ & 0.18 & 0.30 \\
\hline $40+$ & $1.88(1.43,2.47)$ & 0.14 & $<0.001$ & $1.64(1.13,2.37)$ & 0.19 & 0.01 \\
\hline Unknown & $0.18(0.10,0.33)$ & 0.30 & $<0.001$ & $0.25(0.10,0.60)$ & 0.45 & 0.002 \\
\hline Asthma & $0.90(0.74,1.10)$ & 0.10 & 0.30 & $0.81(0.59,1.11)$ & 0.16 & 0.19 \\
\hline Hypertension & $0.92(0.78,1.08)$ & 0.08 & 0.31 & $1.12(0.88,1.42)$ & 0.12 & 0.35 \\
\hline Diabetes & $1.28(1.09,1.50)$ & 0.08 & 0.002 & $1.56(1.25,1.96)$ & 0.11 & $<0.001$ \\
\hline Cancer & $1.10(0.91,1.31)$ & 0.09 & 0.32 & $1.00(0.78,1.30)$ & 0.13 & 0.97 \\
\hline Chronic kidney disease & $1.16(0.96,1.39)$ & 0.09 & 0.12 & $1.52(1.17,1.98)$ & 0.13 & 0.002 \\
\hline COPD & $1.19(0.95,1.49)$ & 0.12 & 0.13 & $1.41(1.02,1.93)$ & 0.16 & 0.04 \\
\hline History of stroke & $1.23(0.98,1.54)$ & 0.12 & 0.08 & $1.52(1.08,2.14)$ & 0.17 & 0.02 \\
\hline Congestive heart failure & $1.67(1.35,2.07)$ & 0.11 & $<0.001$ & $1.14(0.84,1.57)$ & 0.16 & 0.40 \\
\hline Cardiovascular disease & $1.08(0.92,1.28)$ & 0.09 & 0.34 & $0.78(0.61,1.00)$ & 0.13 & 0.05 \\
\hline
\end{tabular}

$B M I$, body mass index; $C I$, confidence interval; $C O P D$, chronic obstructive pulmonary disease; Ref., Reference Group; $S E$, standard error

${ }^{a}$ Regression models adjusted for all variables in the table, and are specific to each time wave in providing adequate support for non-English speakers, ranging from limited in-person interpreter access (e.g., due to infection control policies) to difficulties hearing or understanding (e.g., due to masks obscuring faces or muffling voices, respiratory symptoms making phone-based interpretation difficult to understand, or delirium assessments not being conducted in the speaker's native language) [20]. Our system responded by implementing additional targeted strategies to support non-English-speaking inpatients. Subsequent progress in wave 2-with language no longer a 
Table 6 Characteristics of patients admitted with COVID-19 who died in-hospital or were discharged to hospice

\begin{tabular}{|c|c|c|c|}
\hline \multirow[t]{2}{*}{ Characteristics } & \multicolumn{2}{|c|}{ Number (\%) of patients } & \multirow[t]{2}{*}{$p$ value* } \\
\hline & $\begin{array}{l}\text { Wave } 1 \\
(n=568)\end{array}$ & $\begin{array}{l}\text { Wave } 2 \\
(n=227)\end{array}$ & \\
\hline \multicolumn{4}{|l|}{ Age } \\
\hline $0-44$ & $7(1.2)$ & $5(2.2)$ & \multirow[t]{5}{*}{0.46} \\
\hline $45-54$ & $19(3.3)$ & $4(1.8)$ & \\
\hline $55-64$ & $57(10.0)$ & $18(7.9)$ & \\
\hline $65-74$ & $121(21.3)$ & $46(20.3)$ & \\
\hline $75+$ & $364(64.1)$ & $154(67.8)$ & \\
\hline \multicolumn{4}{|l|}{ Sex } \\
\hline Male & $324(57.0)$ & $137(60.3)$ & \multirow[t]{2}{*}{0.39} \\
\hline Female & $244(43.0)$ & 90 (39.6) & \\
\hline \multicolumn{4}{|l|}{ Race/ethnicity } \\
\hline White & $388(68.3)$ & $166(73.1)$ & \multirow[t]{5}{*}{0.64} \\
\hline Black & $56(9.9)$ & $19(8.4)$ & \\
\hline Other & $25(4.4)$ & $11(4.8)$ & \\
\hline Hispanic & $80(14.1)$ & $26(11.4)$ & \\
\hline Unknown & $19(3.3)$ & $5(2.2)$ & \\
\hline \multicolumn{4}{|l|}{ Primary language } \\
\hline English & 447 (78.7) & $182(80.2)$ & \multirow[t]{3}{*}{0.49} \\
\hline Non-English & $113(19.9)$ & $44(19.4)$ & \\
\hline Unknown & $8(1.4)$ & $1(0.4)$ & \\
\hline \multicolumn{4}{|l|}{ Insurance type } \\
\hline Commercial & $188(33.1)$ & $69(30.4)$ & \multirow[t]{3}{*}{0.55} \\
\hline Medicaid & $29(5.1)$ & $9(4.0)$ & \\
\hline Medicare & $351(61.8)$ & $149(65.6)$ & \\
\hline \multicolumn{4}{|l|}{ SVI } \\
\hline Q1 (0-.25) & $71(12.5)$ & $29(12.8)$ & \multirow[t]{5}{*}{0.16} \\
\hline Q2 (.25-.50) & $84(14.8)$ & 49 (21.6) & \\
\hline Q3 (.50-.75) & $128(22.5)$ & $41(18.1)$ & \\
\hline Q4 (.75-1) & $158(27.8)$ & $56(24.7)$ & \\
\hline Unknown & $127(22.4)$ & $52(22.9)$ & \\
\hline \multicolumn{4}{|l|}{ Admit source } \\
\hline Nursing home facility & $54(9.5)$ & $16(7.0)$ & \multirow[t]{2}{*}{0.27} \\
\hline Other & $514(90.5)$ & $211(92.9)$ & \\
\hline \multirow[t]{2}{*}{ Characteristics } & \multicolumn{2}{|c|}{ Number (\%) of patients } & \multirow[t]{2}{*}{$p$ value } \\
\hline & $\begin{array}{l}\text { Wave } 1 \\
(n=5844)\end{array}$ & $\begin{array}{l}\text { Wave } 2 \\
(n=4007)\end{array}$ & \\
\hline \multicolumn{4}{|l|}{ Smoking status } \\
\hline Current/former smoker & $296(52.1)$ & $121(53.3)$ & \multirow[t]{3}{*}{0.32} \\
\hline Non-smoker & $226(39.8)$ & $81(35.7)$ & \\
\hline Unknown & $46(8.1)$ & $25(11.0)$ & \\
\hline BMI & & & \\
\hline Normal (18.5-25) & $192(33.8)$ & $86(37.9)$ & 0.82 \\
\hline Underweight $(<18.5)$ & $37(6.5)$ & $13(5.7)$ & \\
\hline Overweight (25-30) & $154(27.1)$ & $58(25.5)$ & \\
\hline Class 1 obese (30-35) & $103(18.1)$ & $42(18.5)$ & \\
\hline Class 2 obese $(35-40)$ & $42(7.4)$ & $17(7.5)$ & \\
\hline Class 3 obese $(40+)$ & $32(5.6)$ & $10(4.4)$ & \\
\hline Chronic conditions & & & \\
\hline 0 & $76(13.4)$ & $38(16.7)$ & 0.09 \\
\hline 1 & $73(12.8)$ & $39(17.2)$ & \\
\hline $2+$ & $419(73.8)$ & $150(66.1)$ & \\
\hline
\end{tabular}

Table 6 (continued)

SVI, Social Vulnerability Index; $B M I$, body mass index

${ }^{*} p$ values for wave 1 versus wave 2 were calculated using a $X^{2}$ test for all variables

significant predictor of poor outcome-suggests it is possible to close language-based COVID-19-related disparity gaps with focused interventions.

Overall, these results underscore the importance of health systems focusing on non-English-speaking primary care patients as an especially vulnerable group for adverse COVID-19-related outcomes. Health systems should consider targeted prevention-focused efforts, which could include regular translation of relevant primary care-based educational materials and funding language-appropriate vaccination campaigns for highly impacted communities. However, whereas most existing COVID-19-related disparity strategies have focused on upstream interventions, this study's findings suggest an additional parallel need for hospital-level policies regarding the care of non-Englishspeaking patients. This could include increasing in-person interpreter availability for non-Spanish languages, investing in video-based interpretation equipment for isolation rooms, and using signs to remind staff of patients' preferred languages. Notably, the COVID-19 virus may be novel, but the health system needs and inequities it is exposing are likely not. Such proposed interventions are likely therefore worthwhile investments to reduce preventable inequitable outcomes for this specific vulnerable population, not just only during the COVID-19 pandemic but also beyond.

\section{Limitations}

This study includes only patients receiving primary care within MGB, a health system that draws patients predominately from MA, a state unique nationally with its low rate of uninsured. This may limit generalizability to other states and with regard to health systems which care for high rates of patients not established with primary care. Patients without ongoing outpatient relationships may have other social risk factors precluding access to care, including being undocumented or a member of a vulnerable minority population, and therefore, our analysis may underestimate the true rate of racial/ethnic and language-based disparities in COVID19 admissions at a community level. Our analysis also cannot account for secular trend, including increased access to vaccinations, improved nationwide availability of novel COVID-19 therapeutics, and generally improved awareness of the public or health care workers in terms of understanding when to seek care. Additionally, it is important to note that perceived improvements in disparities (e.g., decreases in the proportion of non-White patients admitted) may not 
translate into true improvements in equity (e.g., if vulnerable patients face increased barriers to accessing hospitallevel care). Finally, this study relies on self-identified race and ethnicity as two separate answers given by the patient and combined into a single race/ethnicity variable. Though paralleling government agency conventions in race/ethnicity reporting, this method likely does not capture the full spectrum of racial/ethnic identity. This may limit generalizability to communities with high rates of multiracial/multiethnic patients, as asking multiracial individuals to identify with conventional categories may result in inaccurate representation of existing disparities [21].

\section{Conclusion}

Comparing two waves of COVID-19 hospital admissions in a large northeastern health system, our analysis demonstrates that significant sociodemographic disparities in COVID-19 hospital admissions improved between temporal waves but continued to persist over a year. Hispanic/Latino and Black individuals, non-English speakers, and residents of socially vulnerable communities continued to be disproportionately represented. Our analysis also identifies non-English-speaking status as a novel significant predictor for COVID-19-related severe illness once hospitalized, but as an addressable risk factor as well. These results underscore the importance for health systems to invest in targeted support of non-English-speaking patients, both in regard to upstream COVID19 prevention in the primary care setting but also in regard to addressing inequities in hospital experience once admitted. Health systems should consider evaluating and improving resources for non-English-speaking patients before the next COVID-19 surge "stress test" reveals—in the form of worsened disparities-that existing supports are insufficient.

Supplementary Information The online version contains supplementary material available at https://doi.org/10.1007/s40615-022-01249-y.

Acknowledgements Contributors: The authors thank program manager Mitch Kellaway in the Mass General Brigham Department of Quality and Patient Experience and Dr. Joseph Betancourt in the Massachusetts General Hospital Disparities Solution Center for their input in regard to race and ethnicity data collection.

Author Contribution All authors contributed to the study conception and design. Data collection and analysis were performed by Nicholas Brisbon, PhD, and Harrison Hubbell, BS. The first draft of the manuscript was written by Priscilla Wang, MD, and all authors commented on prior versions of the manuscripts. All authors read and approved the final manuscript.

\section{Declarations}

Conflict of Interest The authors declare no competing interests.

\section{References}

1. Van Dyke ME, Mendoza MCB, Li W, et al. Racial and ethnic disparities in COVID-19 incidence by age, sex, and period among persons aged $<25$ years - 16 U.S. Jurisdictions, January 1-December 31, 2020. MMWR Morb Mortal Wkly Rep. 2021;70(11):382-388. Published 2021 Mar 19. https://doi.org/ 10.15585/mmwr.mm7011e1

2. Rubin-Miller L, Alban C, Artiga S, et al. COVID-19 racial disparities in testing, infection, hospitalization, and death: analysis of epic patient data. Kaiser Family Foundation. https://www. kff.org/coronavirus-covid-19/issue-brief/covid-19-racial-dispa rities-testing-infection-hospitalization-death-analysis-epic-patie nt-data/. Published Sept 6, 2020. Accessed July 1, 2021.

3. Gross CP, Essien UR, Pasha S, Gross JR, Wang SY, NunezSmith M. Racial and ethnic disparities in population-level Covid-19 mortality. J Gen Intern Med. 2020;35(10):3097-9. https://doi.org/10.1007/s11606-020-06081-w.

4. Escobar GJ, Adams AS, Liu VX, et al. Racial disparities in COVID-19 testing and outcomes: retrospective cohort study in an integrated health system [published online ahead of print, 2021 Feb 9]. Ann Intern Med. 2021;M20-6979. https://doi.org/ 10.7326/M20-6979.

5. Maness SB, Merrell L, Thompson EL, Griner SB, Kline N, Wheldon C. Social determinants of health and health disparities: COVID-19 exposures and mortality among African American people in the United States. Public Health Rep. 2021;136(1):1822. https://doi.org/10.1177/0033354920969169.

6. Tai DBG, Shah A, Doubeni CA, Sia IG, Wieland ML. The disproportionate impact of COVID-19 on racial and ethnic minorities in the United States. Clin Infect Dis. 2021;72(4):703-6. https://doi.org/10.1093/cid/ciaa815.

7. Cummings MJ, Baldwin MR, Abrams D, et al. Epidemiology, clinical course, and outcomes of critically ill adults with COVID-19 in New York City: a prospective cohort study. Lancet. 2020;395(10239):1763-70. https://doi.org/10.1016/S01406736(20)31189-2.

8. Buikema AR, Buzinec P, Paudel ML, et al. Racial and ethnic disparity in clinical outcomes among patients with confirmed COVID-19 infection in a large US electronic health record database. EClinicalMedicine. 2021;39:101075. https://doi.org/10. 1016/j.eclinm.2021.101075.

9. Gallo Marin B, Aghagoli G, Lavine K, et al. Predictors of COVID-19 severity: a literature review. Rev Med Virol. 2021;31(1):1-10. https://doi.org/10.1002/rmv.2146.

10. Ponti G, Maccaferri M, Ruini C, Tomasi A, Ozben T. Biomarkers associated with COVID-19 disease progression. Crit Rev Clin Lab Sci. 2020;57(6):389-99. https://doi.org/10.1080/10408 363.2020.1770685.

11. Ogedegbe G, Ravenell J, Adhikari S, et al. Assessment of racial/ethnic disparities in hospitalization and mortality in patients with COVID-19 in New York City. JAMA Netw Open. 2020;3(12):e2026881. Published 2020 Dec 1. https://doi.org/ 10.1001/jamanetworkopen.2020.26881

12. Atkeson A, Cooper R. States address racial and ethnic disparities in their COVID-19 responses and beyond. National Academy of State Health Policy. Available at https://www.nashp.org/ states-address-racial-and-ethnic-disparities-in-their-covid-19responses-and-beyond/. Accessed July 1, 2021.

13. Melnik M, Raisz A, Pearlman J. Across two waves: COVID-19 disparities in Massachusetts. Boston Indicators. COVID Community Data Lab website. Available at https://www.bostonindi cators.org/reports/report-website-pages/covid_indicators-x2/ 2020/december/persisting-covid-disparities. Accessed July 1, 2021. 
14. Agency for Toxic Substances and Disease Registry. CDC/ATSDR Social Vulnerability Index (SVI). Centers for Disease Control website. Available at https://www.atsdr.cdc.gov/placeandhealth/ svi/index.html. Accessed July 1, 2021.

15. Centers for Disease Control. COVID-19: medical conditions. Centers for Disease Control website. https://www.cdc.gov/coron avirus/2019-ncov/need-extra-precautions/people-with-medicalconditions.html. Accessed July 1, 2021.

16. Fox J, Weisberg S. An R companion to applied regression. 3rd ed. Thousand Oaks: SAGE Publications; 2019.

17. QuickFacts: Massachusetts. United States Census Bureau; 2019. Available at https://www.census.gov/quickfacts/MA. Accessed July $1,2021$.

18. Ingraham NE, Purcell LN, Karam BS, et al. Racial/ethnic disparities in hospital admissions from COVID-19 and determining the impact of neighborhood deprivation and primary language.
Preprint. medRxiv. 2020;2020.09.02.20185983. Published 2020 Sep 3. https://doi.org/10.1101/2020.09.02.20185983

19. Fielding-Miller RK, Sundaram ME, Brouwer K. Social determinants of COVID-19 mortality at the county level. Preprint. medRxiv. 2020;2020.05.03.20089698. Published 2020 Jul 1. https://doi.org/10.1101/2020.05.03.20089698

20. Bebinger $M$. The pandemic imperiled non-English speakers in a hospital. NPR. Available at https://www.npr.org/sections/healthshots/2021/04/23/989928262/the-pandemic-imperiled-non-engli sh-speakers-in-a-hospital. Accessed July 1, 2021.

21. Bratter JL, Gorman BK. Does multiracial matter? A study of racial disparities in self-rated health. Demography. 2011;48(1):127-52. https://doi.org/10.1007/s13524-010-0005-0.

Publisher's Note Springer Nature remains neutral with regard to jurisdictional claims in published maps and institutional affiliations. 